\title{
Microstructure, Mechanical Properties and in vitro Biological Behavior of Silicon Nitride Ceramics
}

\author{
Cecilia Chaves Guedes-Silva ${ }^{a *}$, Andrea Cecilia Dorion Rodas ${ }^{b}$, \\ Antonio Carlos Silva ${ }^{a}$, Christiane Ribeiro ${ }^{b}$, Flávio Machado de Souza Carvalho ${ }^{c}$, Olga Zazuco Higa ${ }^{a}$, \\ Thiago dos Santos Ferreira ${ }^{a}$

\begin{abstract}
anstituto de Pesquisas Energéticas e Nucleares - IPEN, Comissão Nacional de Energia Nuclear CNEN, Avenida Prof. Lineu Prestes, 2242, 05508-000, São Paulo, SP, Brasil

${ }^{b}$ Centro de Engenharia, Modelagem e Ciências Sociais Aplicadas, Universidade Federal do ABCUFABC, Alameda da Universidade $s / n^{\circ}$, 09606-045, São Bernardo do Campo, SP, Brasil

Paulo, SP, Brasil
\end{abstract} \\ 'Instituto de Geociências- IGC, Universidade de São Paulo-USP, 05508-080, Rua do Lago 562, São
}

Received: April 11, 2018; Revised: July 14, 2018; Accepted: August 19, 2018

\begin{abstract}
The bioinert surface of silicon nitride ceramics led us to investigate the additions of $\mathrm{SiO}_{2}, \mathrm{CaO}$ and $\mathrm{Al}_{2} \mathrm{O}_{3}$ in order to aid the liquid phase sintering and improve the mechanical properties and biological behavior of the final materials. The sintered materials reached ca. $97 \%$ of theoretical density and total $\alpha \rightarrow \beta-\mathrm{Si}_{3} \mathrm{~N}_{4}$ transformation. The samples had relatively high values of fracture toughness while their elastic modulus values were lower than those of conventional silicon nitride ceramics. Apatite deposits were observed on the surfaces analyzed after SBF (simulated body fluid) immersions, suggesting their bioactivity. Osteoblasts proliferation and calcified matrix were also detected as response to cells/ materials contact. This combination of properties suggests that all studied compositions are promising for applications in biomedical devices. Moreover, compositions with alumina additions and higher silica content had better in vitro biological behavior, densification and mechanical properties, suggesting greater potential to be used in bone substitute devices.
\end{abstract}

Keywords: silicon nitride, sintering, mechanical properties, SBF, MG63 cells.

\section{Introduction}

Silicon nitride is a covalent ceramic widely used in many structural applications due to its excellent mechanical properties, such as high flexural strength, high hardness and relatively high fracture toughness ${ }^{1}$. These properties are due to elongated $\beta-\mathrm{Si}_{3} \mathrm{~N}_{4}$ grains that promote an interlocking microstructure produced by solution-reprecipitation mechanisms during liquid phase sintering ${ }^{2}$. After cooling, the liquid phase will remain in the grain boundaries and triple points of the $\beta-\mathrm{Si}_{3} \mathrm{~N}_{4}$ grains as an amorphous or partially crystalline phase, affecting the microstructure of the sintered material. The type, amount and combination of additives influence the viscosity of the liquid phase, and also control the interfacial strength, morphology and growth of $\mathrm{Si}_{3} \mathrm{~N}_{4}$ grains. Thus, it is evident that the resulting secondary phase plays a fundamental role in controlling the properties and characteristics of ceramics ${ }^{3,4}$.

On the other hand, the interest in using silicon nitride in biomedical applications has increased in recent decades, with works on biocompatibility and in vivo reactivity evidencing its potential in hard tissue surgeries ${ }^{5-14}$. The good performance of silicon nitride in biological environments was demonstrated by its non-cytotoxicity ${ }^{9,15,16}$, high antibacterial

*e-mail: cecilia.guedes@ipen.br. function and better osseointegration than titanium and PEEK (polyether ether ketone) implants ${ }^{17,18}$. Unlike metal devices, silicon nitride is a partially radiolucent material ${ }^{19}$, producing no distortion in radiographic images and allowing an accurate view of the implant during surgical procedure and in postoperative evaluation.

Previous works also related the silicon nitride ability to promote intense bone growth and bone apposition on its surface when installed in rabbit tibia, with a bone formation process similar to that found for titanium implants ${ }^{10}$. This means that silicon nitride is a bioinert material with a good biological response, as also detected by Neumann et al. ${ }^{20}$ in their in vivo studies with alumina and silicon nitride ceramics. A good way to improve bioactivity and promote faster and stronger silicon nitride osseointegration is coating its surface with a hydroxyapatite layer or even producing composites with a

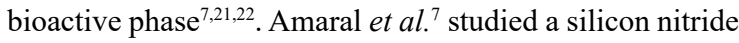
composite containing a bioglass of composition (in wt.\%) $45.0 \mathrm{SiO}_{2}-24.5 \mathrm{Na}_{2} \mathrm{O}-24.5 \mathrm{CaO}-\mathrm{P}_{2} \mathrm{O}_{5}$. However, in addition to the previous preparation of the bioglass by melting, adding an extra step to the processing of the material, the authors used hot pressing for the materials consolidation, which is an extremely costly sintering technique. Also, the low softening temperature of the glass limited the sintering temperature and damaged the $\alpha \rightarrow \beta-\mathrm{Si}_{3} \mathrm{~N}_{4}$ transformation, which is required 
to ensure better mechanical properties to the material. Frajkorová et al. ${ }^{21}$ also studied silicon nitride biocomposites containing the $45.0 \mathrm{SiO}_{2}-24.5 \mathrm{Na}_{2} \mathrm{O}-24.5 \mathrm{CaO}-\mathrm{P}_{2} \mathrm{O}_{5}$ bioglass, although aiming to obtain porous bodies. In this case, the materials were pressureless sintered in air at only $900{ }^{\circ} \mathrm{C}$, also resulting in large amounts of residual $\alpha-\mathrm{Si}_{3} \mathrm{~N}_{4}$.

Thus, the present work aims to obtain silicon nitride ceramics with high amount of $\beta-\mathrm{Si}_{3} \mathrm{~N}_{4}$ by using, as sintering aids, oxides with compositions similar to those used to produce some bioactive glasses ${ }^{22}$. The oxides $\left(\mathrm{SiO}_{2}, \mathrm{CaO}\right.$ and $\left.\mathrm{Al}_{2} \mathrm{O}_{3}\right)$ are introduced during the grinding step of the processing, eliminating the need to obtain the glass previously, so that the compositions could be sintered by liquid phase using the simple pressureless sintering method. These means that the selected additives were added to enable the formation of a liquid phase during the sintering process, which tends to solidify in a vitreous phase with bioactive composition similar to that studied by Ohura et $\mathrm{al}^{22}$.

With the presence of this bioactive glassy phase, the reactions expected to occur in vivo on the material surface would be similar to those promoted by the so-called Bioglass developed by Hench et al. ${ }^{23}$. Due to these reactions, which may be reproduced in vitro with SBF (simulated body fluid), an apatite layer forms on the ceramic surface. Each of the added oxides should contribute to the reactions of apatite formation. Calcium oxide $(\mathrm{CaO})$ should help the first step of the reactions due to the release of $\mathrm{Ca}^{2+}$ ions from the surface via an exchange with $\mathrm{H}_{3} \mathrm{O}^{+}$ions present in the SBF. And silicon oxide $\left(\mathrm{SiO}_{2}\right)$ tends to promote the formation of Si-OH groups, as a consequence of the ion exchange favored by the first step described above, inducing apatite nucleation ${ }^{23}$. Besides, bioactive glasses tend to support the adhesion, maturation and proliferation of human osteoblastlike cells, promoting a complete fusion between the bone tissue and the material surface ${ }^{24-26}$.

Additions of $\mathrm{Al}_{2} \mathrm{O}_{3}$ are also used in view of this oxide assists silicon nitride sintering and considering it is helpful to strengthen the mechanical properties of silica glasses ${ }^{27}$. However, the concentration of this oxide in studied compositions was limited to $1.5 \mathrm{wt}$. \% of the total additives, since higher contents may inhibit bone binding, as observed in other studies ${ }^{28}$.

Hence, this work investigates the influence of $\mathrm{SiO}_{2}, \mathrm{CaO}$ and $\mathrm{Al}_{2} \mathrm{O}_{3}$ on the densification, microstructure, mechanical properties and potential reactivity in vitro for bone repair of silicon nitride ceramics.

\section{Experimental Procedure}

\subsection{Samples preparation}

The starting materials used were: $\mathrm{Si}_{3} \mathrm{~N}_{4}$ (SN-E10 $\alpha-\mathrm{Si}_{3} \mathrm{~N}_{4}$ powder, UBE); $\mathrm{Al}_{2} \mathrm{O}_{3}(99.9 \%$ purity, CT $3000 \mathrm{SG}$ Almatis); $\mathrm{SiO}_{2}$ (quartz, 99.9\% purity, Sigma-Aldrich); and
$\mathrm{CaCO}_{3}$ (P.A., Vetec). Different compositions with 10 to $20 \mathrm{wt} . \%$ of additives, prepared according to Table 1, were ground in a high energy mill at $400 \mathrm{rpm}$ for 4 hours, dried in rotoevaporator and compacted as pellets by uniaxial ( 50 $\mathrm{MPa}$ ) and cold isostatic (200 $\mathrm{MPa}$ ) pressing.

The pellets were embedded into a bed of $\mathrm{Si}_{3} \mathrm{~N}_{4}$ powder in a graphite crucible to be sintered at $1815^{\circ} \mathrm{C}$ for 1 hour, using a graphite resistance furnace (Thermal Technology) under nitrogen atmosphere.

\subsection{Characterization}

The apparent density of the sintered samples was determined by the Archimedes method, and the relative density calculated considering the theoretical density - previously calculated using the mixing rule. The $\alpha \rightarrow \beta-\mathrm{Si}_{3} \mathrm{~N}_{4}$ transformation and the crystalline phases formed in the grain boundaries were evaluated by X-ray powder diffraction (XRPD) (Bruker D8 $\mathrm{X}$-ray diffractometer, $\mathrm{CuK} \alpha$ radiation). The porosity, as well as the morphology and grain size, were analyzed by scanning electron microscopy (SEM) (PHILIPS - XL30 microscope) in polished and plasma etched samples using $\mathrm{SF}_{6}$ and $\mathrm{O}_{2}$.

\subsection{Mechanical properties}

The Young modulus (E) was determined by a nondestructive dynamic method (ASTM E 1876-15) from vibration frequencies (resonance) of the specimens and their geometric parameters, according to Spinner \& Tefft model, in the flexion mode (Grindosonic MKS 5 Instrument). The hardness $\left(\mathrm{H}_{\mathrm{V}}\right)$ and fracture toughness $\left(\mathrm{K}_{\mathrm{Ic}}\right)$ were determined using the Vickers indentation method (Buhler VH1150 Durometer), with the fracture toughness values calculated by the equation proposed by Anstis et al. ${ }^{29}$.

\subsection{Simulated body fluid}

The biological behavior was evaluated by reactivity tests in SBF. Is was used a ratio of $0.1 \mathrm{~cm}^{-1}$ between the total sample area and the solution volume. Duplicate disk-shaped specimens were immersed in SBF during 16 days and the solution was changed every 84 hours. The specimens were removed from SBF immersion every 4 days and their surfaces were characterized by backscattered scanning electron microscopy (Hitachi TM 3000 microscope) and Fourier transform infrared spectroscopy (Thermo Nicolet 670 - FTIR - NEXUS). The spectra were collected in the diffuse reflectance (DRIFT)

Table 1. Studied compositions (wt.\%)

\begin{tabular}{lcccc}
\hline Sample & $\mathbf{S i}_{3} \mathbf{N}_{\mathbf{4}}$ & $\mathbf{S i O}_{2}$ & $\mathbf{C a O}$ & $\mathbf{A l}_{2} \mathbf{O}_{3}$ \\
\hline SSC-06 & 90 & 6 & 4 & 0 \\
SSC-06A & 90 & 6 & 3.85 & 0.15 \\
SSC-10 & 80 & 10 & 10 & 0 \\
SSC-12 & 80 & 12 & 8 & 0 \\
SSC-12A & 80 & 12 & 7.7 & 0.3 \\
\hline
\end{tabular}


mode in the $4000-400 \mathrm{~cm}^{-1}$ spectral range, at 126 scans per sample and a resolution of $2 \mathrm{~cm}^{-1}$.

\subsection{In vitro cell behavior}

MG63 osteoblast-like cells (ATCC) were cultured in Minimum Essential Medium (MEM) (Gibco), supplemented with $10 \%$ fetal bovine serum (Cultilab) and $1 \%$ antibiotic/ antimycotic solution (Gibco) at $37{ }^{\circ} \mathrm{C}$ under a humidified atmosphere and $5 \% \mathrm{CO}_{2}$. When they reached $80 \%$ of confluence, they were washed with PBS (phosphate-buffered saline) and detached with trypsina $0.05 \%$-EDTA $0.02 \%$ solution (Sigma) at $37^{\circ} \mathrm{C}$ for $5 \mathrm{~min}$. The cells were collected and centrifuged for $5 \mathrm{~min}$ at $3000 \mathrm{rpm}$ and resuspended in MEM medium.

Prior to use, discs of silicon nitride with dimension of 10 $\mathrm{mm} \times 2 \mathrm{~mm}$ were sterilized in an autoclave at $121^{\circ} \mathrm{C}$ for 20 min. Each disc was placed in a single well of 24-well culture plates and $1 \mathrm{~mL}$ of culture medium was added for wetting the system for 40 minutes. After this time, the previous medium was changed by a suspension with $2 \times 10^{4}$ MG-63 cells. The plates were placed in a $37^{\circ} \mathrm{C}$ incubator and the culture medium was changed every 3 days.

After culturing for 3, 5, 7 and 14 days, the discs were removed from the original plate and transferred to a cleaned and sterile one. The discs were washed with PBS and the viable cells attached to samples were quantified by MTS assay. The MTS (Promega) reagent was diluted with the culture medium as recommended by the supplier. The volume of culture medium was standardized as $500 \mu \mathrm{L}$ for all samples. After $2 \mathrm{~h}$ incubation, supernatant aliquots of $100 \mu \mathrm{l}$ were transferred to a 96-well plate and the absorbances at 492 $\mathrm{nm}$ read using an Elisa Plate Reader. The amount of viable cells was calculated with a calibration curve (cell number $\mathrm{X}$ absorbance).

The cell morphology and adhesion on samples were observed using SEM (Hitachi TM 3000 microscope) after formaldehyde fixation and dehydration treatments. The mineralization was observed under light and confocal microscopes (Olympus BX51 and Olympus LEXT OLS4100) after staining the cells with an aqueous solution containing 2\% Alizarin Red S (Sigma-Aldrich), pH 4.2.

\section{Results and Discussion}

\subsection{Densification and microstrucuture}

Table 2 shows the density values of the sintered samples. The used compositions led to high relative density, evidencing the good performance of the amount and type of additives to promote the sintering of silicon nitride with the heat treatment conditions used in this study. The larger amount of oxides introduced in SSC-10, SSC-12 and SSC-12A coded samples resulted in a slight increase in the density values, possibly due to the larger amount of liquid phase formed in the sintering process. The presence of $\mathrm{Al}_{2} \mathrm{O}_{3}$ in SSC-06A and SSC-12A samples also led to a slight increase in the relative density values as compared to SSC-06 and SSC-12 samples of the same compositions, but $\mathrm{Al}_{2} \mathrm{O}_{3}$-free. Also, higher calcia content improves densification, with the SSC-10 sample having the highest relative density value. These results indicate that the features of the liquid (i.e, solubility, wetting, viscosity, etc.) with $\mathrm{Ca}-\mathrm{Si}-\mathrm{Al}-\mathrm{O}-\mathrm{N}$ composition or with high $\mathrm{Ca}^{2+}$ content are more suitable to promote the liquid sintering process.

The X-ray diffraction in Figure 1a showed total $\alpha \rightarrow \beta$ $\mathrm{Si}_{3} \mathrm{~N}_{4}$ transformation in all the studied samples. It was also possible to identify $\mathrm{Si}_{2} \mathrm{ON}_{2}$ peaks in samples with high silica contents, i.e., in SSC-12 and SSC-12A. This phase could be formed during cooling by crystallization from the liquid phase $\mathrm{e}^{30}$ or by the reaction between $\alpha-\mathrm{Si}_{3} \mathrm{~N}_{4}$ and $\mathrm{SiO}_{2}{ }^{31}$. Despite the presence of $\mathrm{Si}_{2} \mathrm{ON}_{2}$, all samples exhibited a similar fibrous lace-like microstructure with high aspect ratio $\beta-\mathrm{Si}_{3} \mathrm{~N}_{4}$ grains surrounded by a Ca-Si-Al-O-N or Ca-Si-O-N grain boundary glassy phase. Figure $1 \mathrm{~b}$ shows the microstructure of SSC-10 sample after polishing and etching representing the microstructure of the five studied compositions.

\subsection{Mechanical properties}

Depending on the prosthesis application, specific values of mechanical properties must be assured (such as hardness, elastic modulus and fracture toughness) either by choosing the appropriate material or controlling the material microstructure during the processing. Improved fracture toughness, for example, is a critical property to select a material which will be loaded during service. Biomaterials

Table 2. Physical properties of the sintered samples

\begin{tabular}{lccccc}
\hline Sample & $\begin{array}{c}\text { Apparent density } \\
\left(\mathbf{g} / \mathbf{c m}^{\mathbf{3}} \mathbf{)}\right.\end{array}$ & $\begin{array}{c}\text { Relative density } \\
\mathbf{( \% )}\end{array}$ & $\begin{array}{c}\text { Young's modulus } \\
\mathbf{( G P a )}\end{array}$ & $\begin{array}{c}\text { Vickers hardness } \\
(\mathbf{G P a})\end{array}$ & $\begin{array}{c}\text { Fracture } \\
\text { toughness } \\
\left(\mathbf{M P a} . \mathbf{m}^{\mathbf{1}} \mathbf{)}\right.\end{array}$ \\
\hline SSC-06 & $3.0019 \pm 0.0046$ & $95.34 \pm 0.14$ & $290.90 \pm 3.57$ & $12.40 \pm 0.29$ & $5.69 \pm 0.50$ \\
SSC-06A & $3.0235 \pm 0.0098$ & $96.01 \pm 0.31$ & $300.73 \pm 7.65$ & $12.17 \pm 0.26$ & $5.59 \pm 0.45$ \\
SSC-10 & $3.0400 \pm 0.0080$ & $97.01 \pm 0.25$ & $265.40 \pm 4.31$ & $10.92 \pm 0.13$ & $5.76 \pm 0.43$ \\
SSC-12 & $2.9957 \pm 0.0216$ & $96.08 \pm 0.69$ & $269.80 \pm 6.39$ & $11.71 \pm 0.42$ & $4.88 \pm 0.52$ \\
SSC-12A & $3.0126 \pm 0.0115$ & $96.59 \pm 0.37$ & $271.63 \pm 3.13$ & $11.07 \pm 0.23$ & $5.70 \pm 0.55$ \\
\hline
\end{tabular}




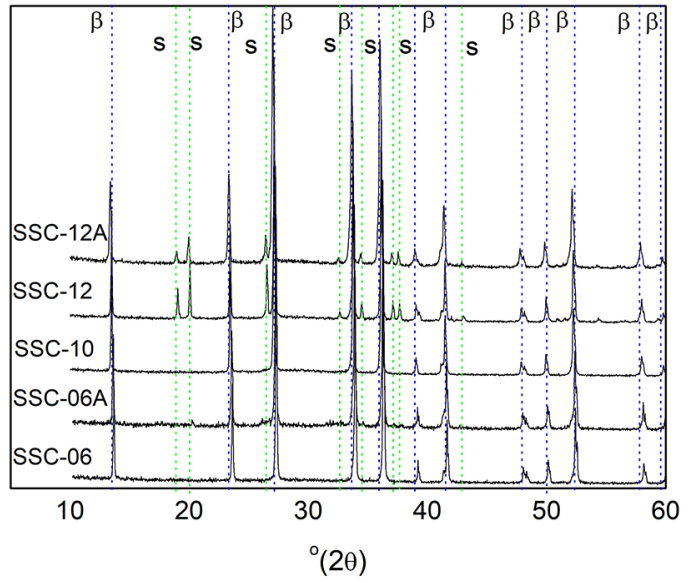

(a)

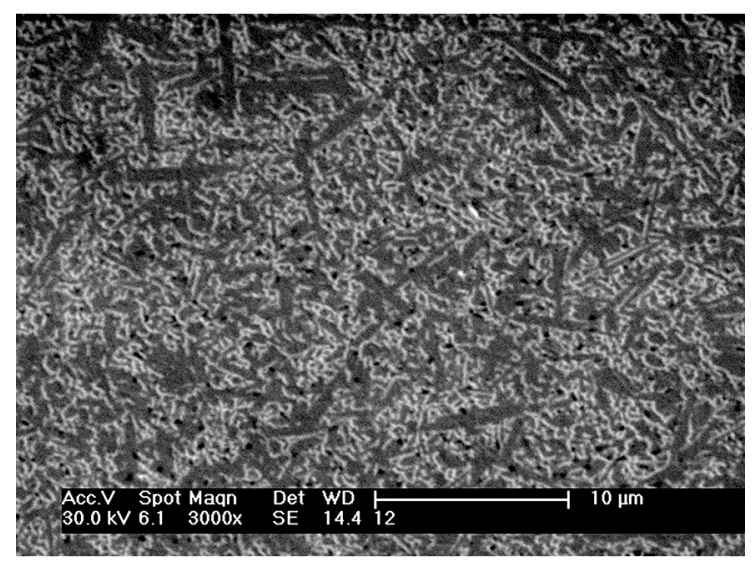

(b)

Figure 1. (a) X-ray powder diffraction patterns of the samples ( $\mathrm{S}$ is the $\mathrm{Si}_{2} \mathrm{ON}_{2}$ phase and $\beta$ is the $\beta-\mathrm{Si}_{3} \mathrm{~N}_{4}$ phase) and (b) scanning electron micrograph of the polished and etched SSC-10 sample.

with low values of fracture toughness have low ability to resist the propagation of pre-existing cracks due to routine patient's activities ${ }^{32-34}$.

For silicon nitride ceramics, the amount and type of additives are primordial factors to control the mechanical properties of the sintered material due to interfacial strength or the $\beta-\mathrm{Si}_{3} \mathrm{~N}_{4}$ grains morphology. From Table 2, it is possible to note no significant difference in the values of fracture toughness, considering the samples compositions, possibly because of their similar microstructures. Such microstructures composed of elongated $\beta-\mathrm{Si}_{3} \mathrm{~N}_{4}$ grains resulted in relatively high values of fracture toughness, analogous to those of silicon nitride ceramics containing rare earth oxides as sintering aids ${ }^{3,35}$, recommended for applications subjected to more severe conditions than those proposed in this study. Hence, these results indicate the materials ability to prevent failure during its handling and during the patient's normal activities, such as chewing, walking, running, etc.

The hardness and elastic modulus were considerably different, yielding smaller values for compositions with greater amount of additives and, consequently, of glassy phase. This reduction is extremely important, since it decreases the difference in relation to the elastic modulus of the cortical bone (15 to $20 \mathrm{GPa}$ ) and, consequently, the probability of device subsidence, although this undesirable effect is not only related to this mechanical property, but also to the design, shape and size of the prosthesis ${ }^{36}$.

\subsection{Reactivity in Simulated Body Fluid (SBF)}

In orthopedics and implantology, the material is considered bioactive when it is integrated with the bone tissue without formation of fibrous tissue at the bone-implant interface ${ }^{23}$. Tests with simulated body fluid are very used to evaluate bioactivity. Many studies have reported that materials able to form apatite on the surface after SBF tests tend to bind to the living bone in short periods during their implantation in vivo. In 2003, Fujibayashi et al. ${ }^{37}$ compared in vivo bone growth and in vitro apatite formation in different $\mathrm{Na}_{2} \mathrm{O}-\mathrm{CaO}-\mathrm{SiO}_{2}$ glasses and confirmed that the evaluation of apatite formation in SBF has a good correlation with in vivo test results.

This good correlation was also detected by Kokubo et $a l .{ }^{38}$. They concluded that the bioactivity of a material in vivo can be predicted in vitro by formation of an apatite layer on its surface after SBF immersions. Many other examples of works confirm the efficiency of SBF tests to evaluate bioactivity of different materials. Here we also cite those with plasma-sprayed $\mathrm{TiO}_{2}$ coatings $^{39}$, phosphosilicate glasses based on Bioglass 45S5 with various amounts of zinc oxides ${ }^{40}$ and nonwoven composite fabric composed of randomly mixed $\mathrm{PCL}$ and $\mathrm{CaO}-\mathrm{SiO}_{2}$ gel fibers ${ }^{41}$.

In this work, the samples surfaces were examined after 4,8 and 16 days of SBF immersion. Backscattered scanning electron micrographs (Figure 2) of the samples indicate that from the 4th day of immersion onwards, a bright phase was formed on the samples surface. In addition, the bright phase increased gradually with immersion time until to form a layer with globular particles, typical of hydroxyapatite ${ }^{38}$.

In Figure 2, it is possible to observe that although the nucleation process had been similar for all samples in 4 days of SBF immersion, the SSC-06A and SSC-12A samples had their nucleation process inhibited on the $8^{\text {th }}$ day. On the other hand, this behavior changed for longer immersion times (16 days of SBF immersion), with the SSC-06A and SSC-12A samples showing higher precipitation on the surface than the SSC-06 and SSC-12 samples, respectively.

This behavior can be explained considering silicate glasses formed by silica tetrahedra connected by oxygen bonds. When these glasses also contain calcium as a network modifier, $\mathrm{Ca}^{2+}$ forms non-bridging oxygen bonds and disrupts the network, increasing the glass reactivity, as happen in $\mathrm{Al}_{2} \mathrm{O}_{3}$-free samples. On SSC-06A and SSC-12A samples, $\mathrm{CaO}$ was partially replaced by alumina (Table 1 ), creating Si-O-Al-Si bonds and reducing the glass reactivity and the calcium phosphate formation ${ }^{42}$. In contrast, after 


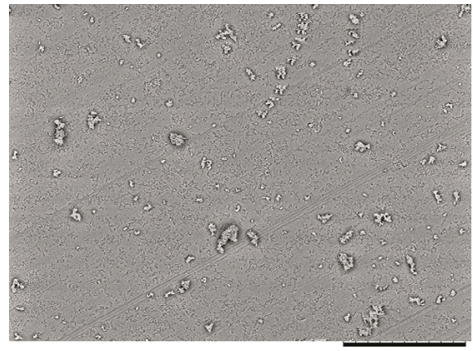

(a) $\overline{100 \mu \mathrm{m}}$

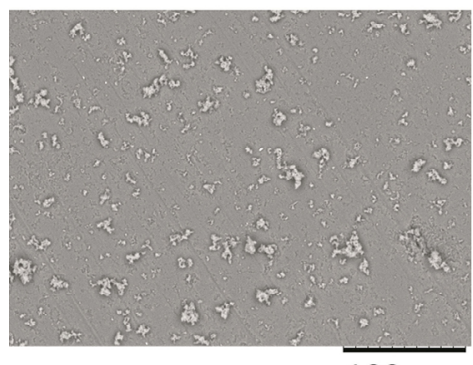

(d)

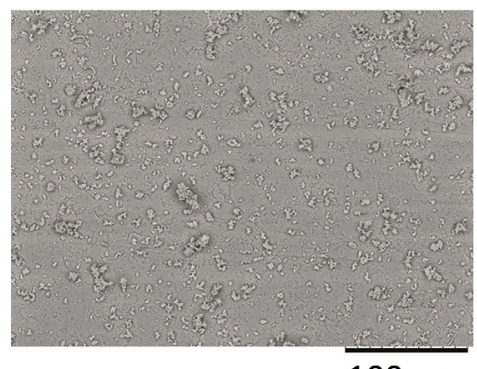

(g) $\quad 100 \mu \mathrm{m}$
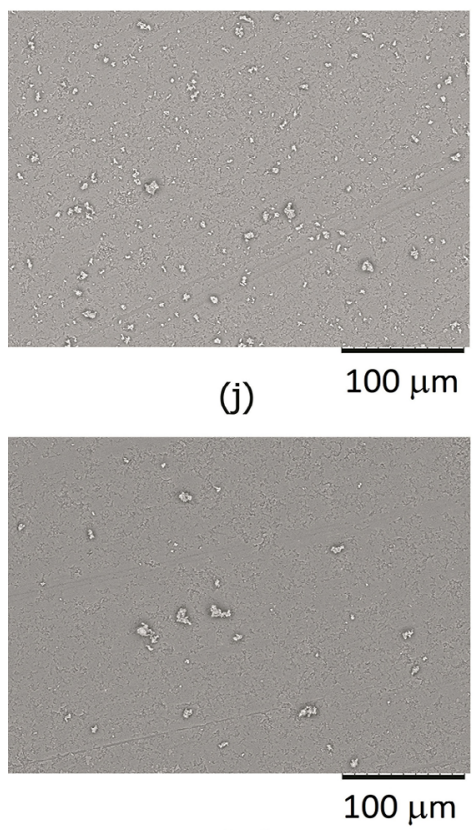

(m)

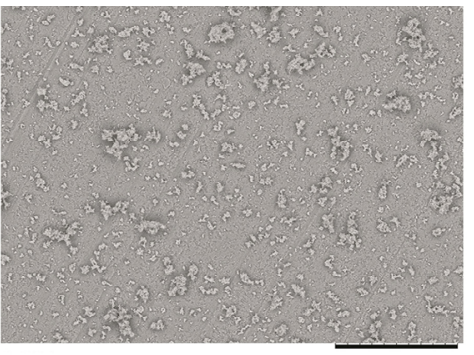

(b) $\quad 100 \mu \mathrm{m}$

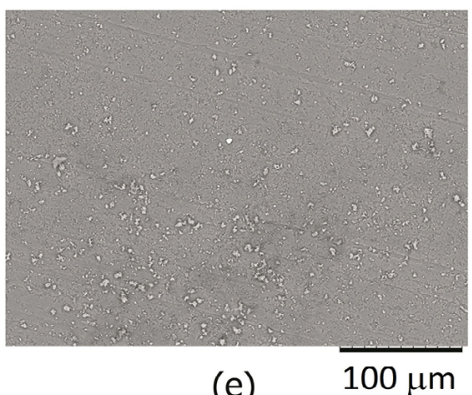

(e) $\quad 100 \mu \mathrm{m}$

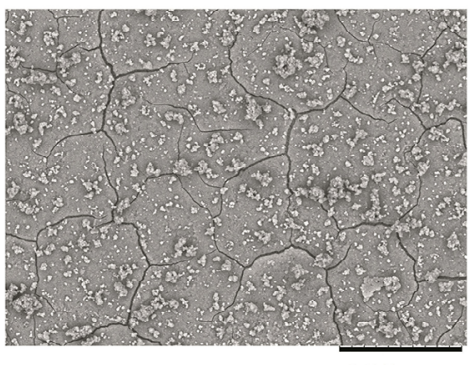

(h)

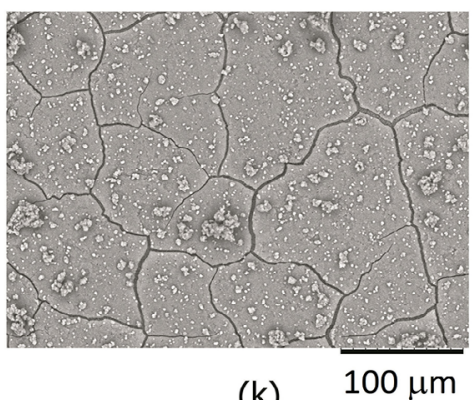

$(\mathrm{k})$

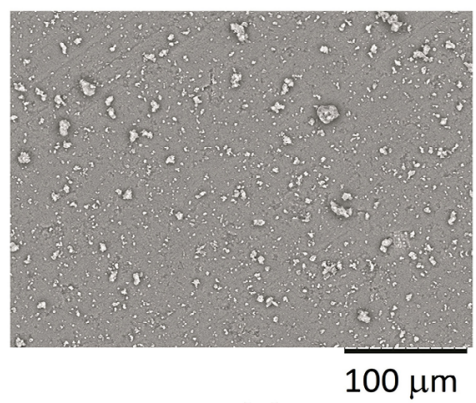

(n)
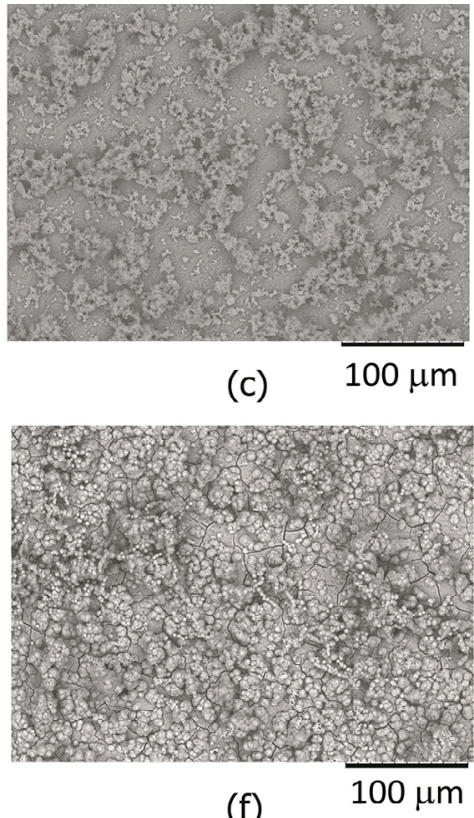

$(f)$
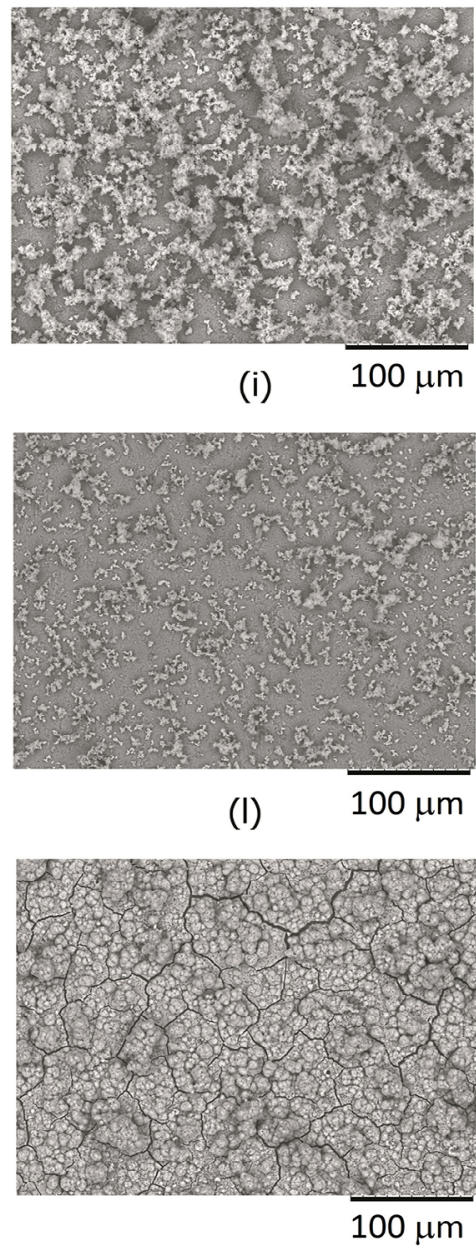

(0)

Figure 2. Images of samples submitted to bioactivity test in SBF after 4, 8 and 16 days of immersion. (a) SSC-06/4 days, (b) SSC-06/8 days, (c) SSC-06/16 days, (d) SSC-06A/4 days, (e) SSC-06A/8 days, (f) SSC-06A/16 days, (g) SSC-10/4 days, (h) SSC-10/8 days, (i) SSC-10/16 days, (j) SSC-12/4 days, (k) SSC-12/8 days, (1) SSC-12/16 days, (m) SSC-12A/4 days, (n) SSC-12A/8 days and (o) SSC-12A/16 days. 
the growth of calcium phosphate nuclei in glasses with $\mathrm{Al}^{3+}$, the apatite layer tends to be more stable due to replacements of $\mathrm{P}_{2} \mathrm{O}_{5}$ by $\mathrm{Al}_{2} \mathrm{O}_{3}{ }^{43}$.

Moreover, Figure 2 shows a slight variation in the apatite deposition on SSC-10 and SSC-12 samples, with the same content of $\mathrm{Si}_{3} \mathrm{~N}_{4}$ but with different silica-to-calcia mass ratio. The greater deposition on SSC-10 reveals the positive effect of a high content of $\mathrm{CaO}$ in the ceramic composition. However, even with the positive effect of $\mathrm{CaO}$, the deposition on SSC-10 did not exceed that on SSC-12A, which confirms that alumina is actually significant to control the dissolution and crystallization reactions of apatite in SBF.

Figure 3 shows the FTIR spectra of the samples before and after immersions in SBF solution. By this figure, it is
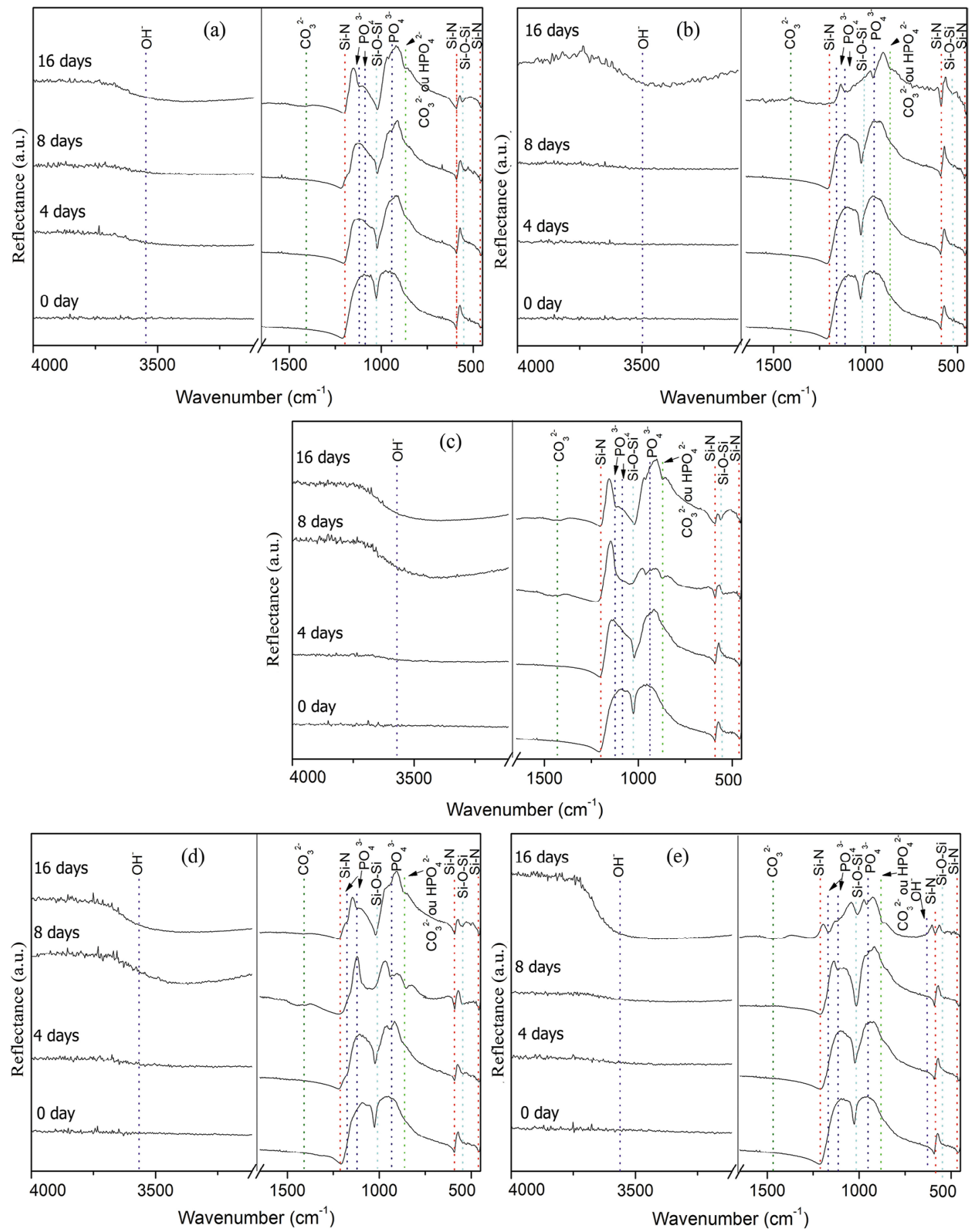

Figure 3. FTIR spectra of the samples surfaces before and after SBF immersions: (a) SSC-06, (b) SSC-06A, (c) SSC-10, (d) SSC12 and (e) SSC-12A. 
possible to follow the evolution of the apatite formation also shown in SEM images of Figure 2. Before immersion, peaks around $460,590,1020$ and $1200 \mathrm{~cm}^{-1}$ are observed as a consequence of the O-Si-O and Si-N vibrations of $\mathrm{Si}_{3} \mathrm{~N}_{4}$, $\mathrm{Si}_{2} \mathrm{ON}_{2}$ and intergranular glassy phase ${ }^{44}$.

Weak peaks associated to phosphate groups $\left(\mathrm{PO}_{4}^{3-}\right)$ around $550 \mathrm{~cm}^{-1}$ and from $\sim 945$ to $\sim 1120 \mathrm{~cm}^{-145-47}$ can be noted on SSC-06, SSC-10 and SSC-12 surfaces after 4 days of SBF immersion. Considering no phosphorus-based compounds were added to initials compositions of the samples, the phosphate ions observed in this assay were supplied only from the surrounding fluid.

Peaks around $873 \mathrm{~cm}^{-1}$ are also present and can correspond to $\mathrm{CO}_{3}^{2-}$ or $\mathrm{HPO}_{4}^{2-}$ vibrations (resulting from the hydrolysis of phosphates occurring in SBF). As the immersion time increases, it is noted the increase of these peaks in all the $\mathrm{Al}_{2} \mathrm{O}_{3}$-free samples. Just as the $\mathrm{Al}_{2} \mathrm{O}_{3}$-free samples, $\mathrm{PO}_{4}{ }^{3-}$ and $\mathrm{CO}_{3}{ }^{2-} / \mathrm{HPO}_{4}{ }^{2-}$ peaks are present in SSC06A and SSC-12A samples surface, but only after 8 days of $\mathrm{SBF}$ immersion, suggesting that $\mathrm{Al}_{2} \mathrm{O}_{3}$ additions delayed the nucleation process, as observed in the SEM results of Figure 2, although no peaks related to Si-O-Al vibrations could be identified in substrates, possibly due to low amount of these chemical bonds.

Peaks of $\mathrm{CO}_{3}^{2-}$ around $1400 \mathrm{~cm}^{-1}$ on surfaces immersed for 16 days suggest the formation of carbonated hydroxyapatite ${ }^{46-48}$, even as peaks around $3500-3600 \mathrm{~cm}^{-1}$ indicate the presence of $\mathrm{OH}^{-}$on a hydrated layer in the materia ${ }^{48}$. In addition, a peak around $640 \mathrm{~cm}^{-1}$ in SSC-12A sample is attributed to $\mathrm{OH}^{-}$vibrations.

These results indicate that the intergranular glassy phases in compositions shown in Table 1 are able to induce the formation of an apatite layer on the materials surfaces (Figures 2 and 3), precisely because of the selected oxide additives. Bock et al. ${ }^{49}$ support that a silicon yttrium aluminum oxynitride glassy phase is promising to form an apatite layer on silicon nitride ceramics. However, analyzing their results of bioactivity in SBF, it is possible to observe merely the presence of isolated islands of $\mathrm{Ca}$ and $\mathrm{P}$ deposits on the material surface after 28 days of immersion. This comparison of results demonstrates the importance of the proper choice of silicon nitride sintering additives when considering its application as biomaterials.

\subsection{In vitro cells behavior}

The MTS assay in silicon nitride samples illustrated in Figure 4 shows that cells grow in appreciable number from 3 days after seeding. These results indicate that the ceramic components are adequate to regulate the bone formation, since the cellular growth (adhesion and proliferation) plays an important role in the healing process.

Moreover, proliferation proceeded more significantly on compositions containing alumina, suggesting that additions of $\mathrm{Al}_{2} \mathrm{O}_{3}$ in SSC-12A e SSC-06A samples favor

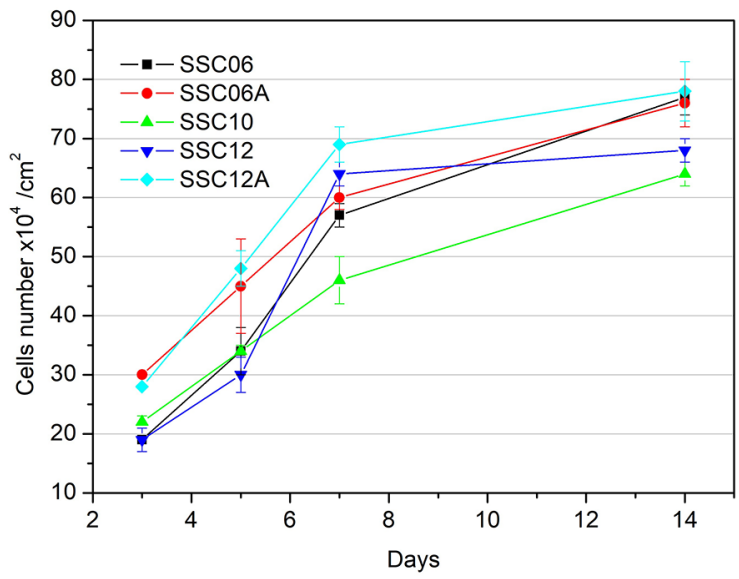

Figure 4. Cell proliferation assays in the studied samples.

a quick osteoblastic proliferation during the first 5 culture days. SSC-06 and SSC-12 $\left(\mathrm{Al}_{2} \mathrm{O}_{3}\right.$-free $)$ also lead to a large cells proliferation but their cells number was similar to that of SSC-06A sample only after 7 culture days. As well as this, the number of cells around the SSC-12 sample did not increase between 7 and 14 culture days. From Figure 5, it is also possible to observe that the slower cells proliferation was obtained around the SSC-10 sample, which has high contents of silica and calcia.

As the greater osteoblasts in vitro proliferation suggests the material has a potential ability to form bone tissue around its surface when installed in vivo ${ }^{50}$, the SSC-12A sample seems to be the more promising studied composition. The high $\mathrm{SiO}_{2}$ concentration combined with $\mathrm{Al}_{2} \mathrm{O}_{3}$ in this composition favored the cell proliferation possibly owing to the high amount of intergranular glassy phase which had good ability to form apatite in SBF tests.

In order to detect the cell adhesion, MG63 cells cultures on the materials were observed by SEM. Together with the detected proliferation on the samples surfaces, MG63 osteoblastlike cells are attached on the samples surfaces and present a normal morphology, as shown by the SEM images of the samples submitted to 3 culture days (Figures $5 \mathrm{a}$ to $5 \mathrm{e}$ ). After this culture time, it is possible to note that the cells filled ca. $55 \%$ of the observed areas and they are growing to cover the entire surface. This trend is verified after 7 culture days (Figures $5 \mathrm{f}$ to $5 \mathrm{j}$ ) when a cell monolayer was formed on all samples surfaces, which is the result of the enhanced proliferation and adhesion results.

These results are similar to those found by Miola et $a l .{ }^{51}$ which observed suitable MG63 cell adhesion on three different bioactive glasses, revealed by the good substrate-cell and cell-cell contacts. Also, Cozza et al. ${ }^{52}$ investigating the biological behavior of bioactive samples containing powders of hydroxyapatite, cuttlefish bone and Bioglass ${ }^{\circledR} 45 \mathrm{~S} 5$, noted that the MG63 osteoblast-like cells started to grown on the materials surfaces after 3 culture days, as observed by the silicon nitride samples studied here (Figures $5 \mathrm{a}$ to $5 \mathrm{e}$ ). 


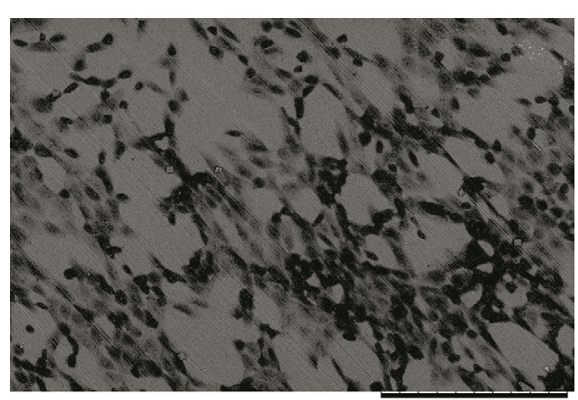

(a)

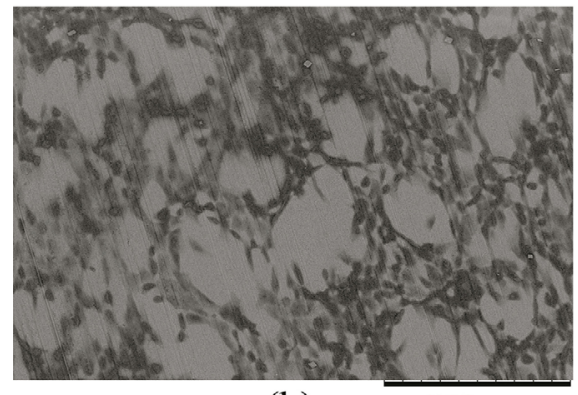

(b)

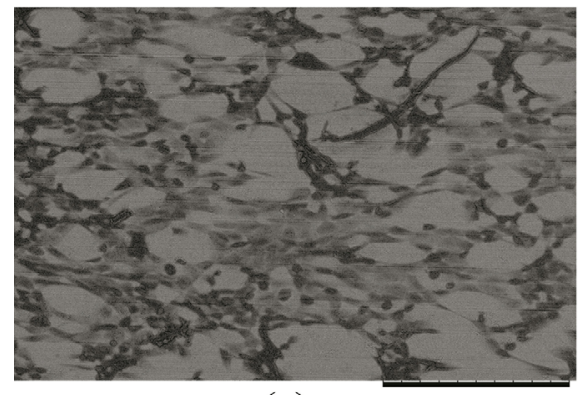

(c)

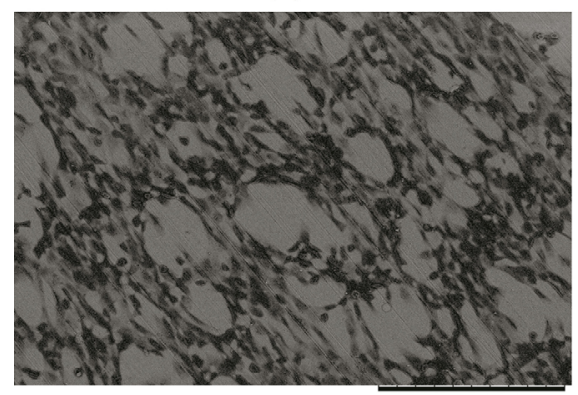

(d)

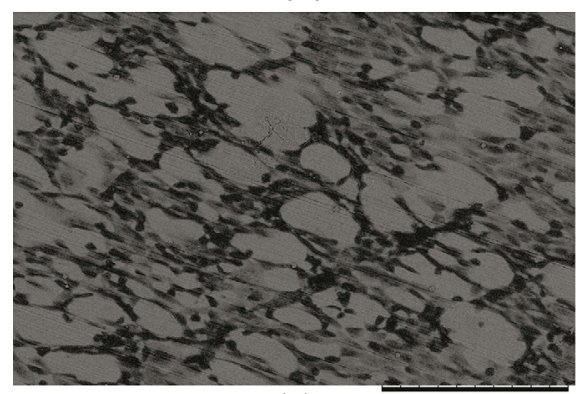

(e)
$300 \mu \mathrm{m}$

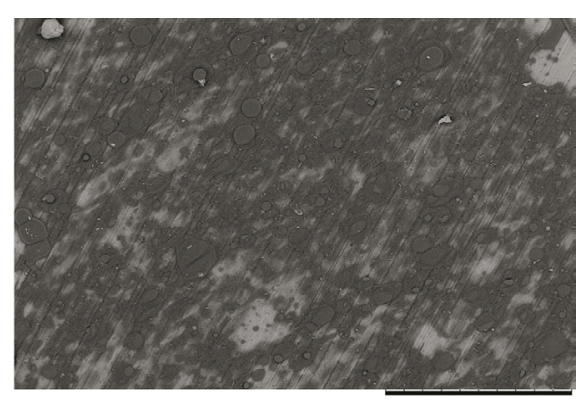

(f)

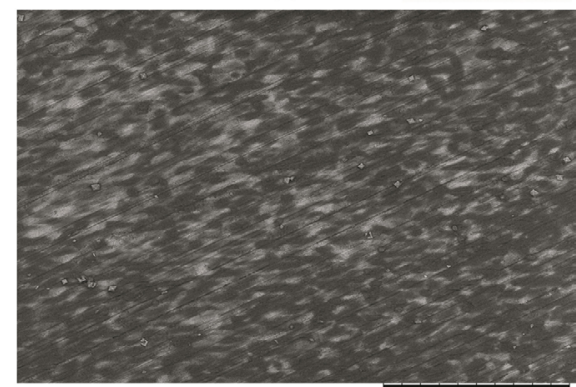

(g)

$300 \mu \mathrm{m}$

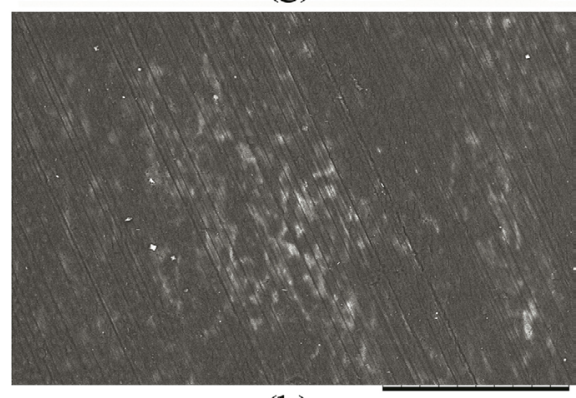

(h)

$300 \mu \mathrm{m}$

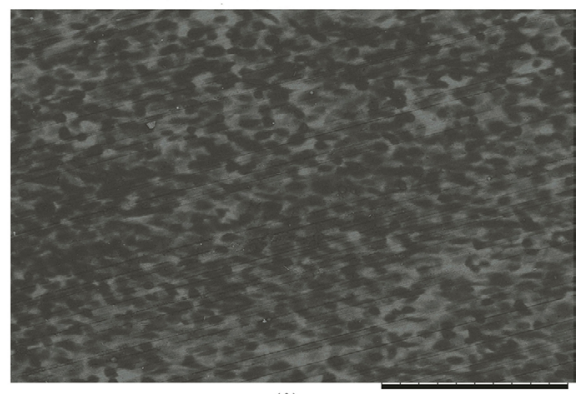

(i)

$300 \mu \mathrm{m}$

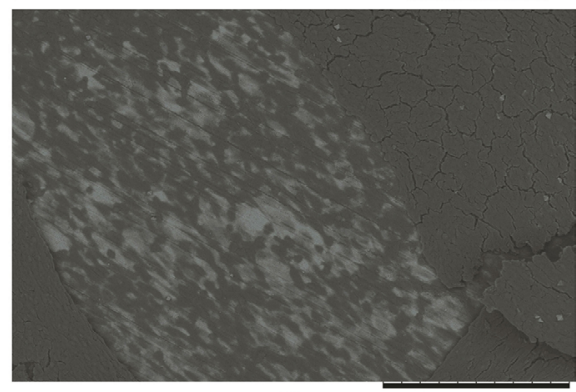

(j)

$300 \mathrm{um}$

Figure 5. Backscattered scanning electron micrographs of MG63 cells after 3 culture days on (a) SSC-06, (b) SSC06A, (c) SSC-10, (d) SSC-12, (e) SSC-12A and after 7 culture days on (f) SSC-06, (g) SSC06A, (h) SSC-10, (i) SSC-12, (j) SSC-12A. 
Although Cozza et al. ${ }^{52}$ have shown that appreciable cellular growth arises in all samples after 7 culture days, a cell monolayer was not formed as happened in this research (Figures $5 \mathrm{f}$ to $5 \mathrm{j}$ ). It shows that the additives oxides used in obtaining silicon nitride ceramics actually support the cells adhesion and proliferation, even without the presence of growth factors or other agents in the culture medium ${ }^{53}$.

Other important response of cell/material contact for bone regeneration is the cell ability to produce calcified matrix. Hence, Figure 6 shows low magnification views of MG63 cells stained with Alizarin Red S after different culture times. This assay allows evaluating the formation of calcium deposits on the surface of materials subjected to osteoblasts cultures. Alizarin Red S reagent may bind to calcium deposits and form salt and chelate ${ }^{54}$ which produce an orange-red color, with brightness proportional to calcium content.

During the first 3 days in culture, detectable amounts of calcium could be revealed with Alizarin Red S staining, demonstrating the formation of mineralization nodules in all samples. Increasing the culture time, the mineralization of the matrix and the nodulus were improved, occupying the total analyzed surfaces areas from 7 culture days. Among the studied samples, the SSC-10 presented greater initial mineral deposition, probably due to the highest calcium concentration in its composition. Also with increasing culture time, it is possible to note that the analyzed areas have an intense orange color as consequence of calcium complexation with the phosphate ions present in culture medium.

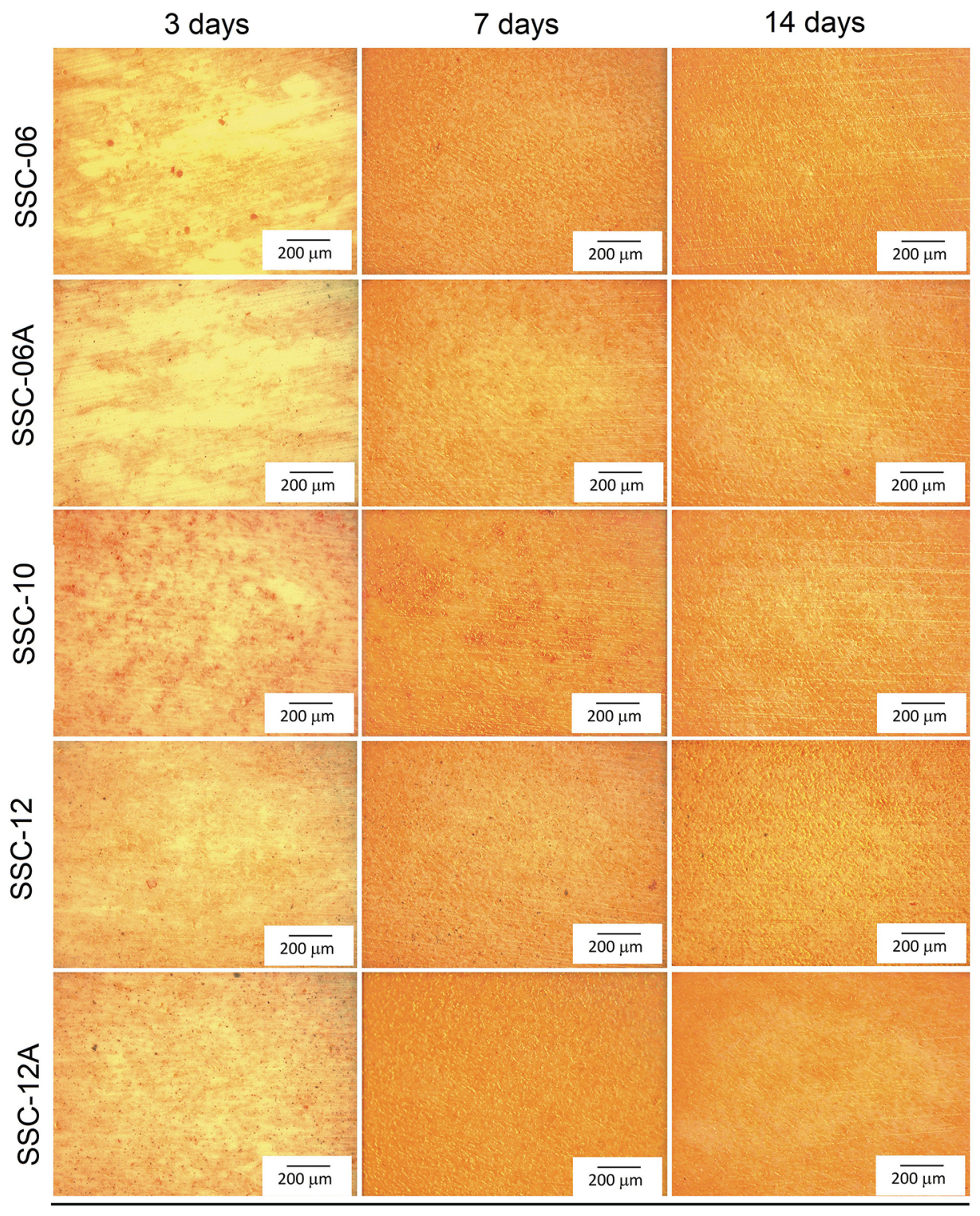

(a)

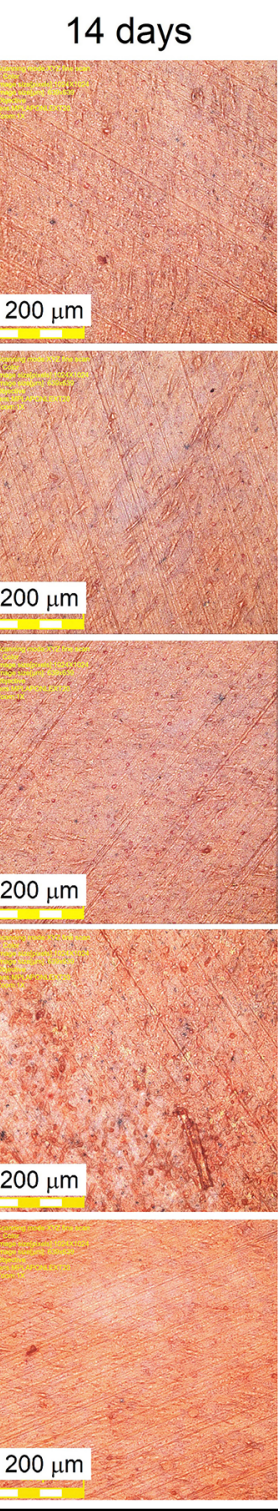

(b)

Figure 6. Images of Alizarin Red S staining of MG63 cells in the presence of samples after 3, 7 and 14 culture days obtained by (a) light microscopy and (b) confocal microscopy. 
Laser confocal microscopy images of osteoblastic cells stained with Alizarin Red S after 14 culture days (Figure 6b) prove mineral deposition for all studied samples. In SSC10 sample, we can observe some nodule-like accumulation of staining, indicating non complexed calcium-containing deposits related to its surface composition, as also shown by light microscopy images (Figure 6a).

Figure $6 \mathrm{~b}$ clearly shows that SSC-12 and SSC-12A samples - with a higher amount of silica - exhibit a brighter and more orange color than others, having SSC-12A sample the most intense orange color. This behavior indicates the calcium complexation with phosphate ions present in the culture medium, suggesting formation of hydroxyapatite, the neo-bone precursor. Then, the SSC-12A seems to be the most promising composition since it could produce more mineralized tissue upon implantation.

\section{Conclusions}

The additives amount and their combination promoted the liquid phase sintering of silicon nitride, yielding a microstructure with interlocked $\beta-\mathrm{Si}_{3} \mathrm{~N}_{4}$ grains and a secondary phase containing an amorphous phase and $\mathrm{Si}_{2} \mathrm{ON}_{2}$. However, the addition of alumina resulted in a slight increase in the relative density of the materials, confirming the efficiency of this oxide as sintering additive for silicon nitride.

Microstructure materials provided relatively high fracture toughness, regardless of their composition. However, the hardness and elastic modulus values varied according to the total amount of additives. The compositions with greater amount of additives had lower hardness and elastic modulus values, suggesting greater potential for bone substitutions.

The presence of alumina significantly favored apatite deposition with increasing immersion time in SBF as well as promoted better cell in vitro proliferation, what tends to result in improved implant-bone fixation and long-term reliability of the device. On the other hand, the Alizarin Red $\mathrm{S}$ assay shown that samples with high content of additives led to better mineralization results.

Hence, all studied compositions have great potential for use in medical applications, although the one containing alumina and larger amount of additives SSC-12A presented the best combination of in vitro biological behavior and mechanical properties. Many components and prosthetic devices can benefit from such properties, whether in maxillofacial surgery, mini-osteofixation systems or even in well-established applications for metal implants, as intervertebral spacers in spine fusion.

\section{Acknowledgments}

The authors are highly grateful to the Laboratory of Amorphous Structures, Rheology and Waste Processing (IPEN/CNEN) for the Fourier transform infrared spectroscopy analysis. Funding: This work was supported by Fundação de Amparo à Pesquisa do Estado de São Paulo, FAPESP (Process 2015/02265-7).

\section{References}

1. Chen F, Cao F, Pan H, Wang K, Shen Q, Li J, et al. Mechanical and dielectric properties of silicon nitride ceramics with high and hierarchical porosity. Materials \& Design. 2012;40:562566.

2. Han W, Li Y, Chen G, Yang Q. Effect of sintering additive composition on microstructure and mechanical properties of silicon nitride. Materials Science and Engineering: A. 2017;700:19-24

3. Tatarko P, Lojanová Š, Dusza J, Šajgalík P. Influence of various rare-earth oxide additives on microstructure and mechanical properties of silicon nitride based nanocomposites. Materials Science and Engineering: A. 2010;527(18-19):4771-4778.

4. Menke Y, Peltier-Baron V, Hampshire S. Effect of rare-earth cations on properties of sialon glasses. Journal of Non-Crystalline Solids. 2000;276(1-3):145-150.

5. Kue R, Sohrabi A, Nagle D, Frondoza C, Hungerford D. Enhanced proliferation and osteocalcin production by human osteoblast-like MG63 cells on silicon nitride ceramic discs. Biomaterials. 1999;20(13):1195-1201.

6. Amaral M, Lopes MA, Santos JD, Silva RF. Wettability and surface charge of Si3N4-bioglass composites in contact with simulated physiological liquids. Biomaterials. 2002;23(20):41234129 .

7. Amaral M, Lopes MA, Silva RF, Santos JD. Densification route and mechanical properties of $\mathrm{Si}_{3} \mathrm{~N}_{4}$-bioglass biocomposites. Biomaterials. 2002;23(3):857-862.

8. Amaral M, Costa MA, Lopes MA, Silva RF, Santos JD, Fernandes $\mathrm{MH} . \mathrm{Si}_{3} \mathrm{~N}_{4}$-bioglass composites stimulate the proliferation of MG63 osteoblast-like cells and support the osteogenic differentiation of human bone marrow cells. Biomaterials. 2002;23(24):4897-4906.

9. Guedes e Silva CC, Higa OZ, Bressiani JC. Cytotoxic evaluation of silicon nitride-based ceramics. Materials Science and Engineering: C. 2004;24(5):643-646.

10. Guedes e Silva CC, König B Jr, Carbonari MJ, Yoshimoto M, Allegrini S Jr, Bressiani JC. Tissue response around silicon nitride implants in rabbits. Journal of Biomedical Materials Research. Part A. 2008;84(2):337-343.

11. Guedes e Silva CC, König B Jr., Carbonari MJ, Yoshimoto M, Allegrini S Jr., Bressiani JC. Bone growth around silicon nitride implants - An evaluation by scanning electron microscopy. Materials Characterization. 2008;59(9):1339-1341.

12. Pezzotti G, Enomoto Y, Zhu W, Boffelli M, Marin E, McEntire BJ. Surface toughness of silicon nitride bioceramics: I, Raman spectroscopy-assisted micromechanics. Journal of the Mechanical Behavior of Biomedical Materials. 2016;54:328-345.

13. McEntire BJ, Enomoto Y, Zhu W, Boffelli M, Marin E, Pezzotti G. Surface toughness of silicon nitride bioceramics: II, Comparison 
with commercial oxide materials. Journal of the Mechanical Behavior of Biomedical Materials. 2016;54:346-359.

14. Bock RM, McEntire BJ, Bal BS, Rahaman MN, Boffelli M, Pezzotti G. Surface modulation of silicon nitride ceramics for orthopaedic applications. Acta Biomaterialia. 2015;26:318-330.

15. Precnerová $M$, Bodišová K, Frajkorová F, Galusková D, Nováková ZV, Vojtaššák J, et al. In vitro bioactivity of silicon nitride-hydroxyapatite composites. Ceramics International. 2015;41(6):8100-8108.

16. Santos C, Ribeiro S, Daguano JKMF, Rogero SO, Strecker K, Silva CRM. Development and cytotoxicity evaluation of SiAlONs ceramics. Materials Science and Engineering: $C$. 2007;27(1):148-153.

17. Gorth DJ, Puckett S, Ercan B, Webster TJ, Rahaman M, Bal BS. Decreased bacteria activity on $\mathrm{Si}_{3} \mathrm{~N}_{4}$ surfaces compared with PEEK or titanium. International Journal of Nanomedicine. 2012;7:4829-4840.

18. Webster TJ, Patel AA, Rahaman MN, Sonny Bal B. Anti-infective and osteointegration properties of silicon nitride, poly(ether ether ketone), and titanium implants. Acta Biomaterialia. 2012;8(12):4447-4454.

19. Arts MP, Wolfs JFC, Corbin TP. Porous silicon nitride spacers versus PEEK cages for anterior cervical discectomy and fusion: clinical and radiological results of a single-blinded randomized controlled trial. European Spine Journal. 2017;26(9):23722379 .

20. Neumann A, Kramps M, Ragoß C, Maier HR, Jahnke K. Histological and microradiographic appearances of Silicon Nitride and Aluminum Oxide in a rabbit femur implantation model. Materials Science \& Engineering Technology. 2004;35(9):569-573.

21. Frajkorová F, Bodišová K, Boháč M, Bartoníčková E, Sedláček J. Preparation and characterisation of porous composite biomaterials based on silicon nitride and bioglass. Ceramics International. 2015;41(8):9770-9778.

22. Ohura K, Nakamura T, Yamamuro T, Kokubo T, Ebisawa $\mathrm{Y}$, Kotoura Y, et al. Bone-bonding ability of $\mathrm{P}_{2} \mathrm{O}_{5}$-Free $\mathrm{CaO}$ $\mathrm{SiO}_{2}$ glasses. Journal of Biomedical Materials Research. 1991;25(3):357-365.

23. Hench LL. Bioceramics: From Concept to Clinic. Journal of the American Ceramic Society. 1991;74(7):1487-1510.

24. Bosetti M, Cannas M. The effect of bioactive glasses on bone marrow stromal cells differentiation. Biomaterials. 2005;26(18):3873-3879.

25. Bosetti M, Zanardi L, Hench LL, Cannas M. Type I collagen production by osteoblast-like cells cultured in contact with different bioactive glasses. Journal of Biomedical Materials Research. Part A. 2003;64(1):189-195.

26. Hoppe A, Güldal NS, Boccaccini AR. A review of the biological response to ionic dissolution products from bioactive glasses and glass-ceramics. Biomaterials. 2011;32(11):2757-2774.

27. Kaur G, Pandey OP, Singh K, Homa D, Scott B, Pickrell G. A review of bioactive glasses: Their structure, properties, fabrication, and apatite formation. Journal of Biomedical Materials Research. Part A. 2014;102(1):254-274.
28. Karlsson KH, Fröberg K, Ringbom T. A structural approach to bone adhering of bioactive glasses. Journal of Non-Crystalline Solids. 1989;112(1-3):69-72.

29. Anstis GR, Chantikul P, Lawn BR, Marshall DB. A Critical Evaluation of Indentation Techniques for Measuring Fracture Toughness: I, Direct Crack Measurements. Journal of the American Ceramic Society. 1981;64(9):533-538.

30. Chadwick MM, Petrovic JJ, Danforth SC, Mitchell TE. Topotactic growth of $\mathrm{Si}_{2} \mathrm{ON}_{2}$ on SiC. Acta Metallurgica et Materialia. 1993;41(2):375-386.

31. Cao GZ, Huang ZK, Fu XR, Yah DS. Phase equilibrium studies in $\mathrm{Si}_{2} \mathrm{~N}_{2} \mathrm{O}$-containing systems: I. Phase relations in the $\mathrm{Si}_{2} \mathrm{~N}_{2} \mathrm{O}-$ $\mathrm{Al}_{2} \mathrm{O}_{3}-\mathrm{Y}_{2} \mathrm{O}_{3}$ system. International Journal of High Technology Ceramics. 1985;1(2):119-127.

32. Taylor D. Measuring fracture toughness in biological materials Journal of Mechanical Behavior of Biomedical Materials. 2018;77:776-782.

33. Seghi RR, Denry IL, Rosenstiel SF. Relative fracture toughness and hardness of new dental ceramics. The Journal of Prosthetic Dentistry. 1995;74(2):145-150.

34. Ichim I, Li Q, Li W, Swain MV, Kieser J. Modelling of fracture behaviour in biomaterials. Biomaterials. 2007;28(7):1317-1326.

35. Guedes-Silva CC, Carvalho FMS, Bressiani JC. Effect of rare-earth oxides on properties of silicon nitride obtained by normal sintering and sinter-HIP. Journal of Rare Earths. 2012;30(11):1177-1183.

36. Cabraja M, Oezdemir S, Koeppen D, Kroppenstedt S. Anterior cervical discectomy and fusion: Comparison of titanium and polyetheretherketone cages. BMC Musculoskeletal Disorders. 2012;13:172.

37. Fujibayashi S, Neo M, Kim HM, Kokubo T, Nakamura T. A comparative study between in vivo bone ingrowth and in vitro apatite formation on $\mathrm{Na}_{2} \mathrm{O}-\mathrm{CaO}-\mathrm{SiO}_{2}$ glasses. Biomaterials. 2003;24(8):1349-1356.

38. Kokubo T, Takadama H. How useful is SBF in predicting in vivo bone bioactivity? Biomaterials. 2006;27(15):2907-2915.

39. Liu X, Zhao X, Li B, Cao C, Dong Y, Ding C, et al. UV-irradiationinduced bioactivity on $\mathrm{TiO}_{2}$ coatings with nanostructural surface. Acta Biomaterialia. 2008;4(3):544-552.

40. Lusvardi G, Zaffe D, Menabue L, Bertoldi C, Malavasi G, Consolo U. In vitro and in vivo behaviour of zinc-doped phosphosilicate glasses. Acta Biomaterialia. 2009;5(1):419-428.

41. Seol YJ, Kim KH, Kim IA, Rhee SH. Osteoconductive and degradable electrospun nonwoven poly(e-caprolactone)/CaO$\mathrm{SiO}_{2}$ gel composite fabric. Journal of Biomedical Materials Research A. 2010;94(2):649-659.

42. Anderson ÖH, Rosenqvist J, Karlsson KH. Dissolution, leaching, and $\mathrm{Al}_{2} \mathrm{O}_{3}$ enrichment at the surface of bioactive glasses studied by solution analysis. Journal of Biomedical Materials Research. 1993;27(7):941-948.

43. El-Kheshen AA, Khaliafa FA, Saad EA, Elwan RL. Effect of $\mathrm{Al}_{2} \mathrm{O}_{3}$ addition on bioactivity, thermal and mechanical properties of some bioactive glasses. Ceramics International. 2008;34(7):1667-1673. 
44. Yokoyama S, Goto H, Miyamoto T, Ikeda N, Shibahara K. Atomic layer controlled deposition of silicon nitride and in situ growth observation by infrared reflection absorption spectroscopy. Applied Surface Science. 1997;112:75-81.

45. Amin MS, Randeniya LK, Bendavid A, Martin PJ, Preston EW. Biomimetic apatite growth from simulated body fluid on various oxide containing DLC thin films. Diamond and Related Materials. 2012;21:42-49.

46. Li HC, Wang DG, Hu JH, Chen CZ. Effect of various additives on microstructure, mechanical properties, and in vitro bioactivity of sodium oxide-calcium oxide-silica-phosphorus pentoxide glass-ceramics. Journal of Colloid and Interface Science. 2013;405:296-304.

47. Kokubo T. Surface chemistry of bioactive glass-ceramics. Journal of Non-Crystalline Solids. 1990;120(1-3):138-151.

48. Stoch A, JastrzębskiW, Brozek A, Trybalska B, Cichocinska M, Szarawara E. FTIR monitoring of the growth of the carbonate containing apatite layers from simulated and natural body fluid. Journal of Molecular Structure. 1999;511-512:287-294.

49. Bock RM, Marin E, Rondinella A, Boschetto F, Adachi T, McEntire BJ, et al. Development of a SiYAlON glaze for improved osteoconductivity of implantable medical devices.
Journal of Biomedical Materials Research. Part B, Applied Biomaterials. 2018;106(3):1084-1096.

50. Denga Y, Zhou P, Liu X, Wang L, Xiong X, Tang Z, et al. Preparation, characterization, cellular response and in vivo osseointegration of polyetheretherketone/nano-hydroxyapatite/ carbon fiber ternary biocomposite. Colloids and Surfaces B: Biointerfaces. 2015;136:64-73.

51. Miola M, Brovarone CV, Maina G, Rossi F, Bergandi L, Ghigo $\mathrm{D}$, et al. In vitro study of manganese-doped glasses for bone regeneration. Materials Science and Engineering: C. 2014;38:107118.

52. Cozza N, Monte F, Bonani W, Aswath P, Motta A, Migliaresi C. Bioactivity and mineralization of natural hydroxyapatite from cuttlefish and Bioglass ${ }^{\circledR}$ co-sintered bioceramics. Journal of Tissue Engineering and Regenerative Medicine. 2018;12(2):e1131-e1142.

53. Agarwal R, García AJ. Biomaterial strategies for engineering implants for enhanced osseointegration and bone repair. Advanced Drug Delivery Reviews. 2015;94:53-62.

54. Moriguchi T, Yano K, Nakagawa S, Kaji F. Elucidation of adsorption mechanism of bone-staining agent alizarin red $\mathrm{S}$ on hydroxyapatite by FT-IR microspectroscopy. Journal of Colloid and Interface Science. 2003;260(1):19-25. 